\title{
Coverage of neonatal screening: failure of coverage or failure of information system
}

\author{
A E Ades, J Walker, R Jones, I Smith
}

\begin{abstract}
Objectives-To evaluate neonatal screening coverage using data routinely collected on the laboratory computer.

Subjects-90 850 births in 14 North East Thames community provider districts over a 21 month period.

Methods-Births notified to local child health computers are electronically copied to the neonatal laboratory computer system, and incoming Guthrie cards are matched against these birth records before testing. The computer records for the study period were processed to estimate the coverage of the screening programme. Results-Out of an estimated 90850 births notified to child health computers, all but $746(0.82 \%)$ appeared to have been screened or could be otherwise accounted for $(0.14 \%$ in non-metropolitan districts, $0.39 \%$ in suburban districts, and $1.68 \%$ in inner city districts). A further 893 resident infants had been tested, but could not be matched to the list of notified resident births. The calculated programme coverage already exceeds the $99.5 \%$ National Audit Programme standard in $7 / 14$ districts. Elsewhere it is not clear whether it is coverage or recording of coverage that is low.
\end{abstract}

Department of Epidemiology and Public Health, Institute of Child Health, 30 Guilford St, London WC1N 1EH, UK

A E Ades

J Walker

Department of Biochemistry, Great Ormond Street Hospital NHS Trust, Great Ormond Street, London WC1N 3JH, UK

$\mathrm{R}$ Jones

Department of Metabolic Medicine, Great Ormond Street Hospital NHS Trust I Smith

Correspondence to: Dr Ades, MRC Health Services Research Collaboration, University of Bristol, Canynge Hall, Whiteladies Road, Bristol BS8 2PR, UK

t.ades@bristol.ac.uk

Accepted 9 January 2001 recently in a report from the UK Nation Screening Committee calling for "evidencebased standards". ${ }^{9}$
However, previous studies have not always been able to distinguish between low coverage and low recording of coverage, and there has been insufficient focus on the methods used. Few laboratories have information systems from which coverage statistics can be routinely extracted, and in multidistrict audits in 1992 and 1998 some $30 \%$ of districts were unable to supply any estimate at all. ${ }^{3}$ We present here the largest evaluation of coverage to be published in the United Kingdom, based on the routine information system of a neonatal laboratory with two way electronic links with local child health computers (CHCs).

\section{Methods}

LABORATORY ADMINISTRATIVE PROCEDURES

The Great Ormond Street NHS Hospital Trust neonatal screening laboratory computer (NEON) has two way links with CHCs in 14 districts in North East Thames. Births to residents of these districts are recorded on CHCs usually within two days, and these records are routinely copied to NEON. Most Guthrie cards reach the laboratory 6-20 days later. ${ }^{10} \mathrm{~A}$ bar coded laboratory number is attached to each card on its arrival and a search is made for a corresponding record on NEON, using name, address, sex, birth date, and birth weight. If a match is found, the laboratory number is entered into the record and an acknowledgement is copied to the relevant CHC ("Matched records"). If a match cannot be found on the day of arrival (about $5 \%$ of cards), a new record is created on NEON ("unmatched cards"). Birth records that are not matched to Guthrie cards are referred to as "unmatched records".

About $1 \%$ of neonatal Guthrie cards received at Great Ormond Street are repeat samples, requested if the first sample was inadequate or gave borderline results. Repeat sample records are usually linked to the record of the original sample, but a new record may be created on NEON if the card is not marked as being a repeat.

Every few months laboratory staff produce and edit a list of unmatched CHC records, by district, for which the laboratory has not received a Guthrie card. This is sent to $\mathrm{CHC}$ managers, who check and annotate records of infants known to have died or moved away, whose Guthrie card was tested elsewhere, or whose parents refused testing. One copy of the amended list is sent back to the laboratory, where it is used to update the computer record. Other copies are sent to district midwifery offices and health visitors so that apparently untested infants can be identified and tested. 
93284 records of births from 1 April 1997 to 31 December 1998

- 1127 records marked as a duplicate record or repeat sample

- 414 duplicate records and repeats not marked as such

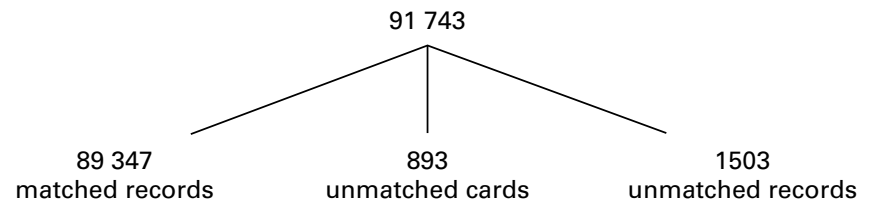

377 tested elsewhere 207 moved away 163 known to have died $\frac{10}{757}$ testing refused 757

$1503-757=746$ apparently untested infants

Figure 1 Breakdown of records of births in 14 North East Thames districts.

DATA ANALYSIS

The analysis was restricted to infants born to residents of the 14 North East Thames districts with two way electronic links to NEON, born over a 21 month period between 1 April 1997 and 31 December 1998. Records identified as repeat samples or duplicate records were deleted. If an unmatched card could be linked to an unmatched CHC record, both were deleted and a new matched record was created. The main matching algorithm required a match on: date of birth, first five letters of the surname, and first six letters of the address; or date of birth and full postcode. Birth weight to within $10 \mathrm{~g}$ or birth rank were included so that records of twins were not counted as duplicates. We have calculated the programme coverage, defined here as the number of infants who have been screened or otherwise accounted for, and its complement, the number of apparently unscreened infants.

Table 1 Births notified to child health computers in the period 1 April 1997 to 31 December 1998, and numbers of matching and non-matching neonatal screening computer (NEON) records

\begin{tabular}{|c|c|c|c|}
\hline Provider district & $\begin{array}{l}\text { Notified } \\
\text { births on } \\
\text { NEON }\end{array}$ & $\begin{array}{l}\text { Births (\%), the neonatal } \\
\text { screening of which is not } \\
\text { accounted for (unmatched } \\
\text { records) }\end{array}$ & $\begin{array}{l}\text { Extra children tested, } \\
\text { not matched to births } \\
\text { (unmatched cards) }\end{array}$ \\
\hline \multicolumn{4}{|l|}{ Non-metropolitan } \\
\hline Basildon & 7474 & $6(0.08)$ & 8 \\
\hline NE Essex & 6210 & $5(0.08)$ & 24 \\
\hline Mid Essex & 6049 & 00 & 37 \\
\hline West Essex & 5844 & $27(0.46)$ & 58 \\
\hline Southend & 6808 & $8(0.12)$ & 19 \\
\hline Subtotal & 32385 & $46(0.14)$ & 146 \\
\hline \multicolumn{4}{|l|}{ Outer London } \\
\hline Barking, Havering \& Brentwood & 9707 & $24(0.25)$ & 18 \\
\hline Redbridge & 5752 & $18(0.31)$ & 45 \\
\hline Waltham Forest & 6358 & $42(0.66)$ & 25 \\
\hline Subtotal & 21817 & $84(0.39)$ & 88 \\
\hline \multicolumn{4}{|l|}{ Inner London } \\
\hline City \& Hackney & 6928 & $118(1.70)$ & 67 \\
\hline Newham & 8028 & $80(1.00)$ & 78 \\
\hline Tower Hamlets & 6203 & $108(1.74)$ & 24 \\
\hline Hampstead & 2685 & $73(2.72)$ & 110 \\
\hline Camden \& Islington & 6474 & $130(2.01)$ & 172 \\
\hline Haringey & 6330 & $107(1.69)$ & 208 \\
\hline Subtotal & 36648 & $616(1.68)$ & 659 \\
\hline Total & 90850 & $746(0.82)$ & 893 \\
\hline
\end{tabular}

*Number of CHC births on neonatal screening computer $=89347$ matched records +1503 unmatched records $=90850$

\section{Results}

There were 93284 records on the laboratory computer belonging to resident infants born in the study period. Of these, 1106 records were marked as repeat samples, and a further 21 records were marked as duplicates. The main matching algorithm identified a further 336 duplicate or repeat records, and 78 more were identified using just two matching variables, leaving 91743 records.

These records represent 89347 matched records, 893 unmatched Guthrie cards, and 1503 unmatched $\mathrm{CHC}$ records (fig 1). Of the unmatched $\mathrm{CHC}$ records, 757 belonged to infants recorded as having been tested elsewhere, moved away, died, or whose parents refused testing. The remaining 746 unmatched records are therefore taken to represent infants who are apparently untested, which is $0.82 \%$ of the total 90850 births notified to CHCs. The proportion apparently untested is highly dependent on district, and considerably lower in non-metropolitan districts $(0.14 \%)$ than in suburban $(0.39 \%)$ or inner city districts (1.68\%) (table 1).

The number of apparently untested infants (746) was similar to the number of unmatched Guthrie cards that could not be attached to a birth record (893). This raised the possibility that some of the unmatched cards belonged in fact to the apparently untested children. The two lists were therefore compared by hand, in order to determine whether names, street addresses, or birth dates had been wrongly entered. It was concluded that only a small proportion, no more than $5 \%$ of the apparently untested infants, could be linked to the unmatched Guthrie cards.

\section{Discussion}

A 1984-1988 review of phenylketonuria screening showed that only one of 455 cases had been missed through a failure of coverage ${ }^{11}$ and none of the 728 cases between 1989 and 1998. ${ }^{12}$ As most untreated phenylketonuria results in profound handicap by 2 years of age, ${ }^{13}$ this would indicate an approximate $99.9 \%$ coverage $(95 \%$ confidence interval $99.44 \%$ to $99.997 \%$ ). This suggests that the low estimates derived from direct studies of coverage, $97.4 \%{ }^{3}$ and $95.8 \%{ }^{4}$, which led to the National Audit project, ${ }^{6}$ along with the $95.8 \%$ figure from the national study itself, may have severely underascertained the true coverage. Further, the proposed national standard of $99.5 \%$ could be seen as insufficiently ambitious, as the data for phenylketonuria suggest that it has already been exceeded.

Detailed consideration of how coverage can be accurately measured has been lacking, and a number of methodological weaknesses can be detected in many of these earlier reports. Because CHC systems receive birth notifications and include fields for the phenylketonuria and congenital hypothyroidism tests, they provide a natural platform for routine coverage estimates. Unfortunately, test results may not always be entered on CHCs, leading to underascertainment of coverage. ${ }^{26}{ }^{14}$ In other studies 
the denominator list may have been overinflated by double counting, as records from multiple sources, such as CHCs, obstetric computers, and laboratory records, appear to have been included. ${ }^{4}$

These difficulties have, in principle, been avoided in this study, which uses CHC birth notifications as a denominator and is based on a system in which the arrival of each Guthrie card is acknowledged and recorded on the $\mathrm{CHC}$ of origin. However, lack of a unique common identifier on $\mathrm{CHC}$ records and on Guthrie cards makes the system described here vulnerable to other risk factors for underascertainment, many of which are more prevalent in inner city areas. These include incomplete recording of perinatal death, movement in and out of the region, failure to recognise repeat samples as such, and difficulty in matching incoming Guthrie cards to birth records because of changes of name and/or address.

Although there was no indication that the unmatched Guthrie cards "belonged to" the unmatched birth records, each must belong to someone, possibly to a child who had been resident in another region at birth but who had moved in later. The existence of these cards in large numbers, which has not been reported in previous direct studies of coverage, illustrates the weakness of the existing information systems. This is reinforced by the disagreement between the average numbers of births notified to North East Thames CHCs and the numbers of birth registrations recorded at the Office for National Statistics: the annual average difference for the years 1992 through 1995 was $0.565 \%,{ }^{15}$ comparable with the $0.82 \%$ unmatched birth records and $0.98 \%$ unmatched Guthrie cards in fig 1.

In spite of this, using the laboratory's routine information system with minimal further processing, we were able to show programme coverage of over $99.9 \%$ in three districts outside London, coverage of over $99.5 \%$ in seven districts, and an average $98.3 \%$ coverage in inner London. The latter figure exceeds the $97.4 \%$ average for Merseyside in $1988 / 89^{3}$ and the $95.8 \%$ reported in two inner London districts in South Thames in $1993^{4}$ and in the National Audit programme, ${ }^{6}$ and suggests that earlier reports of low coverage may have been unduly pessimistic.

It is significant that previous studies reporting higher coverage locally or regionally have relied on either careful case by case tracing of those apparently untested or dedicated well coordinated local staff. ${ }^{2358}$ A notable exception is the $99.93 \%$ coverage reported in Birmingham as early as 1986 , using a routine laboratory information system linked to local CHCs. ${ }^{7}$ This was the inspiration for the North Thames system, but has the additional advantage of having a unique identifier, the $\mathrm{CHC}$ sequence number, printed on to the Guthrie card. Using this system, the West Midlands neonatal laboratory has been able to consistently record coverage far in excess of the $99.5 \%$ recommended coverage standard.

\section{Key messages}

- Coverage of neonatal screening is higher than recent reports suggest, but it is difficult to distinguish failure to screen from failure to record screening

- Coverage of neonatal screening must be monitored accurately both for clinical and public health reasons

- The new system for issuing NHS numbers at birth will provide a basis for a reliable information system of neonatal screening

- A national network encompassing neonatal laboratories and maternity and child health computers is needed to ensure that testing is carried out and the results recorded, regardless of where the parents are living, where the sample is taken, and where the tests are carried out

Screening coverage does need to be monitored closely for both clinical and public health reasons. Firstly, admission to special care units is known to be associated with a higher risk of failure to screen. Children with congenital hypothyroidism are at risk of perinatal problems, and have been missed or screened late for this reason. ${ }^{16}{ }^{17}$ This could become a serious issue if screening is extended to include a wider range of metabolic disorders, ${ }^{13}$ some of which can result in admittance to hospital in the first week of life. Secondly, neonatal screening for sickle cell disease throughout the United Kingdom has been recommended, but accurate local data on coverage are required to determine whether a selective or universal screening strategy would be the most cost effective for each district. ${ }^{18}$

The new system for assigning NHS numbers, to be implemented before the end of 2002, will create an opportunity to develop a reliable neonatal screening information system on a national scale. The proposal is that maternity computers issue NHS numbers at delivery, and it is also intended that the NHS number will be printed on to Guthrie cards. Accurate reliable local routine monitoring of neonatal screening coverage could then follow, but will require that maternity computers and neonatal laboratory computers are both linked into a national network of $\mathrm{CHCs}$ or their future equivalents, to ensure that results are recorded against the correct child's record, wherever the child is resident and wherever the tests are carried out. An operational information system of this sort could measure coverage accurately, could flag up warnings on unscreened children, and could allow assessment of efforts to improve performance, lending itself to continual quality improvement. ${ }^{19}$ Development of such a system would be more useful than attempts to compare inadequately estimated coverage with arbitrary national standards, ${ }^{6}$ or attempts to develop "evidence-based" standards. ${ }^{9}$

The authors thank the staff of the Neonatal Screening Laboratory at Great Ormond Street NHS Trust, those at McKesson HBOC who support the NEON system, and Shirley Thompson who was instrumental in setting it up. 
Contributors: This study was conceived by A E A. J W processed the NEON data and drafted the results. The NEON system was designed by the Signet (now McKesson HBOC) community systems team, who develop and support the Regional Interactive Child Health System (RICHS) in the former North East Thames Region, to a specification conceived by R J with input from A E A.

Funding: J W was supported by a Medical Research Council grant.

Conflicts of interest: none.

1 Elliman D, Garner J. Review of neonatal screen programme for phenylketonuria. BMf 1991;303:471.

2 Jolly, K. Neonatal screening programme for phenylketonuria. BMF 1991;303:716

3 Pharoah POD, Madden MP. Audit of screening for congenital hypothyroidism. Arch Dis Child 1992;67:10736.

4 Streetly A, Grant C, Bickler G, et al. Variation in coverage by ethnic group of neonatal (Guthrie) screening programme in south London. BMF 1994;309:372-4.

5 Simpson N, Randall R, Lenton S, et al. Audit of neonatal screening programme for phenylketonuria and congenital hypothyroidism. Arch Dis Child Fetal Neonatal Ed 1997;77: F228-34

6 Streetly A, Corbett V. The National Newborn Screening Programme: an audit of phenylketonuria and congenital hypothyroidism screening in England and Wales. London: hypothyroidism screening in England and Wales. London: Department of Public Health Medici

7 Griffiths PD, Morris J, Assheton J, et al. An on-line compuGriffiths PD, Morris J, Assheton J, et al. An on-line compu-
terised system for neonatal screening. In: Therrell BL, ed. terised system for neonatal screening. In: Therrell $\mathrm{BL}$, ed. 741. Amsterdam: Elsevier Science, 1987.
8 Tapin D, Girdwood R, Kennedy R, et al. An audit of infants 'unscreened' by the neonatal screening system in Scotland during 1991. Screening 1995;3:201-7.

9 Balmer S, Bowens A, Bruce E, et al. Quality management for screening: report to the UK National Screening Committee. London: Department of Health, 2000.

10 Ades AE, Walker J, Thompson S, et al. Obstacles to timely neonatal screening in North Thames. F Med Screen 1998;5: $183-6$.

11 Smith I, Cook B, Beasley M. Review of neonatal screening programme for phenylketonuria. BMf 1991;303:333-5.

12 Costello PM, Bailey J, Brand MP, et al. Performance of the neonatal screening programme for phenylketonuria (PKU): 1989-93 and 1994-98 compared with 1984-88 [abstract]. Arch Dis Child 1999;80(suppl 1):A2.

13 Pollitt RJ, Green A, McCabe CJ, et al. Neonatal screening for inborn errors of metabolism: cost, yield and outcome. Health Technol Assess 1997;1:1-203.

14 Cappuccio F, Hickman M, Barker M. Neonatal screening: performance is hard to monitor. BMF 1996;312:182.

15 Regional Reproductive Review Information Project. Birth Notification Details by Area of Residence 1993-1995. London: Notification Details by Area of Residence 1993-1995. London: Department of Environmental and Preventive Medicine,
Wolfson Institute of Preventive Medicine, 1997:1-28.

16 Fernhoff PM, Brown AL, Elsas LJ. Congenital hypothyroidism: increase risk of neonatal morbidity results in delayed treatment. Lancet 1997;ii:490-1.

17 Grant DB, Smith I. Survey of neonatal screening for congenital hypothyroidism in England, Wales and Northern Ireland, 1982-84. BMF 1988;296:1355-8.

18 Zeuner D, Ades AE, Karnon J, et al. Antenatal and neonatal Zeuner D, Ades AE, Karnon J, et al. Antenatal and neonatal haemoglobinopathy screening in the UK: review an

19 Wheeler DJ. Understanding variation: the key to managing chaos. Knoxville, TN: SPC Press Inc, 1986.

\section{Narrative Based Medicine, An Interdisciplinary Conference}

\section{Research, Narrative, and Practice}

A two day conference-Monday 3rd and Tuesday 4th September 2001

\section{Homerton College, Cambridge, UK}

\section{BMF Publishing Group}

For full details contact: BMA/BMJ Conference Unit, Tavistock Square, London, WC1H 9JP Tel: +44 (0)20 7383 6819; fax: +44 (0)20 7383 6663; email: clyders@bma.org.uk.

www.quality.bmjpg.com 